\title{
BREVE REFLEXÃO SOBRE A CONSTRUÇÃO DA IDEIA DE PROTEÇÃO SOCIAL E O DIREITO À SAÚDE NA CONSTITUIÇÃO FEDERAL DE 1988
}

\author{
Edith Maria Barbosa Ramos ${ }^{80}$ \\ Isadora Moraes Diniz ${ }^{81}$
}

Recebido em: 31/08/2016

Aprovado em: 15/12/2016

\begin{abstract}
RESUMO
O presente artigo objetiva realizar uma análise inicial do processo da formulação da ideia de direito à saúde como direito social, integrante do rol de direitos fundamentais insculpidos na Constituição Federal de 1988. Para tanto realiza-se uma breve incursão histórica no processo de construção da concepção de proteção social no mundo. Objetiva-se, ainda, analisar a proteção social enquanto fator basilar da cidadania, a seguridade social como núcleo do Estado de Bem-Estar e discutir o contexto de inserção da questão do direito à saúde na agenda pública. O presente trabalho utiliza o método analítico, através da apropriação dos conceitos de proteção social e direitos sociais busca uma reflexão sobre as determinações dos conteúdos presentes na concepção de direito à saúde.
\end{abstract}

Palavras-chave: Proteção Social. Direito à Saúde. Constituição Federal.

\section{INTRODUÇÃO}

O presente artigo objetiva analisar o processo de formulação da ideia de direito à saúde como direito social, integrante do rol de direitos fundamentais insculpidos na Constituição Federal de 1988. Para tanto realiza uma breve incursão histórica no processo de construção da concepção de proteção social.

\footnotetext{
${ }^{80}$ Pós-doutora em Direito Sanitário pela Fundação Oswaldo Cruz - FIOCRUZ/Brasília/DF. Doutora em Políticas Públicas pela Universidade Federal do Maranhão - UFMA. Mestra em Direito pela Universidade Federal de Minas Gerais. Bacharela em Direito pela UFMA. Professora do Departamento de Direito e do Mestrado em Direito e Instituições do Sistema de Justiça da UFMA.

${ }^{81}$ Mestra em Direito e Instituições do Sistema de Justiça pela UFMA. Pós-graduanda em Direito Processual Civil pela Damásio Educacional. Bacharela em Direito pela UFMA.
} 
Objetiva-se analisar a proteção social enquanto fator basilar da cidadania, a partir das reflexões desenvolvidas por Marshall (1967). Destaca-se que no século XIX a pobreza era vista como desvio de caráter, uma propensão individual à vagabundagem e mendicância. Perspectiva que vinculou intrinsecamente a possibilidade de assistência a prestação de um trabalho correspondente. Empreende-se demonstrar que as causas efetivas da pobreza deixaram de ser consideradas, pois foram subestimados os efeitos sociais das transformações econômicas e políticas.

Busca-se, ainda, demonstrar a pobreza como produto do desenvolvimento predatório do capitalismo e que as mobilizações das classes trabalhadoras modificaram significativamente a arena política, a moldura jurídica e o conceito de cidadania no século XX. Coloca-se em evidência a necessidade de reinvenção do capitalismo, no período seguinte à Segunda Grande Guerra, e como foi forjado o modelo de Estado de Bem-Estar Social.

Destaca-se a ideia de mínimos sociais e a inserção dos direitos sociais como elemento integrante do status da cidadania. Aborda-se a seguridade social como núcleo do Estado de Bem-Estar e discute-se o contexto de inserção da questão do direito à saúde na agenda pública. Evidencia-se os principais documentos internacionais para demonstrar que o direito à saúde está relacionado com as condições de vida das pessoas e que a Constituição brasileira de 1988 representa instrumento singular na proteção do direito à saúde no país. $\mathrm{O}$ direito à saúde, no Brasil, esta inserto no capítulo sobre a seguridade social, fundamentada nos princípios da universalidade e da igualdade. Por fim, destaca-se que o direito à saúde ultrapassa questões biológicas, e que inclui a questão social em seu cerne. Ressalta-se a criação do Sistema Único de Saúde e analisa-se as interfaces do direito à saúde, em especial, seus princípios e diretrizes norteadores.

Por essa razão, o presente trabalho utiliza o método analítico, através da apropriação dos conceitos de proteção social e direitos sociais busca uma reflexão das determinações dos conteúdos presentes na concepção de direito à saúde, para posteriormente, analisar criticamente a ideia de cidadania. Deve-se ressaltar que se procurou a superação de posturas metodológicas rígidas, demarcando a análise em diversas variáveis contextuais (jurídico, sociais, econômicas e políticas) a fim de que se evitasse considerações maniqueístas e sem objetivação científica e se conseguisse empreender uma investigação socialmente situada. 
Não há como discutir direito à saúde sem antes fazer uma incursão, ainda que breve, na temática da proteção social enquanto fator basilar da cidadania, que, segundo Marshall (1967), está dividida em três elementos: o civil, o político e o social, os quais, ao menos na sociedade inglesa (que é a analisada na obra do autor), foram se desenvolvendo e se incorporando ao conceito durante três séculos.

O elemento civil da cidadania formou-se no decorrer do século XVIII, sobretudo, em razão do trabalho dos tribunais, que, pouco a pouco foram adicionando ao status do homem livre uma série de direitos essenciais ao exercício da liberdade individual, quais sejam: a liberdade de ir e vir; a liberdade de imprensa, pensamento e fé; o direito à propriedade e o de concluir contratos válidos; o direito à justiça; e o direito de trabalhar.

Já os direitos políticos começaram a ser formados no século XIX, "quando os direitos civis ligados ao status de liberdade já haviam conquistado substância suficiente para justificar que se fale de um status geral de cidadania” (MARSHALL, 1967, p. 69). A formação destes direitos não se caracteriza pelo surgimento de novos direitos, mas sim pela distribuição de velhos direitos a vários setores da população marginalizados politicamente. Dessa forma, paulatinamente ampliaram-se aos indivíduos o direito à participação no exercício do poder político, como um membro de um organismo investido da autoridade política ou como um eleitor dos membros de tal organismo.

Os direitos sociais, por sua vez, passaram a compor o status da cidadania somente no século XX. No entanto, as bases incipientes dos serviços públicos como prestação do Estado começaram a ser lançadas ainda no século XIX com a Lei dos Pobres de 1834, que previa a concessão de prestações sociais pelo Estado não enquanto direitos, mas segundo o paradigma da caridade a fim de aliviar os efeitos indesejados da miséria extrema.

Nessa época, os indivíduos para se valerem da assistência social precisavam se despir de todos os direitos de cidadania, renunciando a sua liberdade, rompendo seus laços familiares e se submetendo a jornadas de trabalho excessivas.

A pobreza era vista quase como um crime, um desvio de caráter que fazia com que o indivíduo, não acometido por qualquer incapacidade, ficasse propenso à vagabundagem e à mendicância. Assim, era dos pobres, portanto, a culpa pela pobreza. Por isso, não poderia haver qualquer assistência sem a prestação de um trabalho correspondente (PEREIRA, 2008).

Dessa forma, durante a vigência da Lei dos Pobres, as verdadeiras causas da pobreza não foram consideradas, na medida em que eram subestimados os efeitos sociais da rápida 
transformação da economia agrária para a industrial, da transferência de forma abrupta da vida social do campo para a cidade, do desemprego decorrente dos avanços tecnológicos, das flutuações dos salários, das precárias, perigosas, insalubres e extenuantes exigências de trabalho e da ausência de educação e lazer. Todos esses elementos expuseram "inevitavelmente a fragilidade da doutrina utilitarista que atribuía ao pobre e às antigas Poor Laws a culpa pelo pauperismo" (PEREIRA, 2008, p. 79). Giovanni (1998, p. 31) destaca, ainda, que:

\begin{abstract}
Inicialmente na Inglaterra e depois nos outros países europeus, os processos de industrialização e urbanização, trouxeram o agravamento dos problemas ligados à pobreza (até então relativamente controlados). As péssimas condições de trabalho vigentes entre a massa proletária que se constituía, o infortúnio, os acidentes, as doenças profissionais e o desemprego tornavam-se cada vez mais evidentes. A conjugação de todos estes fatores - aliada à crescente organização das classes trabalhadoras através de sindicatos, a constituição de partidos políticos de inspiração socialista comunista ou laborista, no bojo da expansão dos direitos políticos evidenciaria, no plano das visões de mundo de então, que a pobreza não era uma decorrência dos méritos (ou deméritos) e performances pessoais, mas um fenômeno ligado a uma relação muito estreita com as condições sociais de vida e, particularmente, de trabalho. Ou pelo menos, que se estava diante de outro tipo de pobreza: não aquela dos parias, dos loucos e doentes, mas a pobreza paradoxal daqueles que trabalhavam.
\end{abstract}

Com efeito, a Revolução Industrial elevou ao máximo a exploração do homem, que era submetido a uma longa jornada de trabalho em troca de um mísero salário, situação que agravou o quadro de pobreza e, por conseguinte, os problemas sociais que a ela se associavam.

Percebeu-se que a pobreza não era fruto da vagabundagem, mas sim produto do próprio desenvolvimento predatório do capitalismo, que explorava ao máximo o trabalho em nome do capital, resultando na contraditória existência da opulência e da riqueza ao lado da miséria absoluta.

Nesse contexto, e como consequência da expansão dos direitos civis e políticos, aumentaram as mobilizações sociais, especialmente dos trabalhadores que lutavam em prol da melhoria das condições de vida e de trabalho, circunstância que, conforme Pereira (2008), resultou nas batalhas pelo alargamento do conceito de cidadania das esferas civil e política para a social, de modo que os trabalhadores passaram a requerer as prestações sociais como direitos devidos pelo Estado.

Polanyi (1980, p. 163-164) observa que a história social e política do século XIX foi marcada por um duplo movimento, que pode ser personificado como:

[...] a ação de dois princípios organizadores da sociedade, cada um deles determinando seus objetivos institucionais específicos, com o apoio de forças sociais definidas e utilizando diferentes métodos próprios. Um foi o princípio do liberalismo econômico, que objetivava estabelecer um mercado auto-regulável, dependia do apoio das classes 
comerciais e usava principalmente o laissez-faire e o livre comércio como seus métodos. O outro foi o princípio da proteção social, cuja finalidade era preservar o homem e a natureza, além da organização produtiva, e que dependia do apoio daqueles mais imediatamente afetados pela ação deletéria do mercado - básica, mas não exclusivamente, as classes trabalhadores e fundiárias - e que utilizava uma legislação protetora, associações restritivas e outros instrumentos de intervenção com seus métodos.

Destarte, se de um lado o paradigma do mercado autorregulável se expandia, do outro cresciam as críticas e as pressões contra o pauperismo das massas, que cada vez mais "ganhavam adeptos e forneciam elementos que justificavam, já no século XIX, a introdução de medidas pontuais de proteção social, ao arrepio dos princípios liberais" (PEREIRA, 2008, p. 81). E em resposta às pressões dos trabalhadores, que tinham suas condições de vida deterioradas, foram lançadas no final do século XIX, no governo alemão de Otto Von Bismarck, as bases da seguridade social, que inclui, dentre outros, os serviços de saúde.

No modelo bismarckiano, somente os trabalhadores e suas famílias podiam usufruir dos benefícios da seguridade social, uma vez que o acesso condicionado a uma contribuição direta anterior (descontada nas folhas de pagamento dos salários) e o montante das prestações era proporcional à contribuição efetuada. O modelo era, portanto, uma espécie de seguro social, que, apesar de representar um avanço na prestação de serviços sociais pelo Estado quando comparado com a Lei dos Pobres de 1834, deixava parte da população fora da cobertura da seguridade social.

O ápice do princípio da proteção social somente foi alcançado após a Segunda Guerra Mundial, quando o capitalismo, diante do quadro de instabilidade política, social e econômica mundial, precisou se reinventar. Em prol da manutenção do modo capitalista, acolheu-se demandas por maior igualdade e reconhecimento dos direitos sociais e segurança econômica, forjando-se um novo modelo de organização estatal - o Estado de Bem-Estar Social, que, ancorando-se nos conceitos de seguridade e cidadania social, assumiu o papel de prover serviços sociais, enquanto direito assegurado pelo Estado e de dimensões quase universais.

Um dos pilares do Welfare State foi o Plano Beveridge, que, formulado durante a Segunda Guerra Mundial na Inglaterra, propôs uma revisão completa do sistema de proteção social inglês, mudando o objetivo dessas políticas, vale dizer, substituindo o escopo de proteção dos trabalhadores contra as situações de risco por um objetivo maior: o combate à pobreza.

No sistema beveridgiano, os direitos sociais passaram a ter caráter universal, destinados incondicionalmente a todos os cidadãos, a fim de garantir a todos que se encontravam em condições de necessidade os mínimos sociais. Conforme Pereira (2000, p. 122-123), 


\begin{abstract}
A partir daí, os mínimos sociais passaram a ter uma conotação mais alargada, incluindo, além de políticas de manutenção de renda - geralmente sob a forma de uma rede de segurança impeditiva do resvalo de cidadãos social e economicamente vulneráveis para baixo de uma linha de pobreza legitimada pela sociedade -, outros mecanismos adicionais de proteção social, como: serviços sociais universais (saúde e educação, por exemplo), proteção ao trabalho (em apoio ao pleno emprego) e garantia do direito ao acesso a esses bens e serviços e ao seu usufruto. Esta foi a fase de ouro das políticas de proteção social, na qual a otimização da satisfação das necessidades humanas básicas tornou-se uma tendência promissora, a partir da Europa.
\end{abstract}

Portanto, segundo Pereira (2008, p. 93), em que pese as críticas que podem ser feitas à ideia de mínimos sociais, "o Sistema de Seguridade Social de Beverigde inovou, de fato, por ser nacional e unificado e conter um eixo distributivo, ao lado do contributivo, além de abolir os testes de meio no âmbito da assistência social".

A prestação dos bens e serviços sociais não envolvia mais a discussão da necessidade (marca das primeiras políticas sociais inglesas que se destinavam àqueles que não poderiam participar do processo produtivo) e tampouco se pautava na base contributiva de cada indivíduo (vale dizer, no quanto cada trabalhador tinha contribuído para o serviço).

No Estado de Bem-Estar Social cabia ao Estado, conforme Marshall (1967, p. 93), garantir "um mínimo de certos bens e serviços essenciais (tais como assistência médica, moradia, educação, ou uma renda nominal mínima ou salário mínimo) a ser gasto em bens e serviços essenciais". É nesse momento em que os direitos sociais se inserem no status da cidadania, passando a provisão de serviços sociais a ser vista enquanto direito de cidadania, que devia ser assegurada a todos os indivíduos independentemente de se situarem nos grupos críticos e da sua inserção no mercado de trabalho.

Dessa forma, como contrapartida ao direito dos indivíduos, exsurgiu o dever do Estado de regulamentar um conjunto de garantias aos cidadãos em situação de fragilidade e infortúnio social. Pereira (2008, p. 88-89) afirma que no Welfare State,

[...] Estado e mercado se articularam e se co-responsabilizaram pela formulação e gerenciamento de políticas favorecedora de pleno emprego e de um conjunto de benefícios e serviços que, na perspectiva dos direitos, asseguravam aceitáveis padrões de vida aos cidadãos, a saber: o seguro social obrigatório, leis de proteção ao trabalho, salários mínimos, ampliação de instituições e serviços de saúde e educação, programas de habitação subsidiados [...] No âmbito das modernas estruturas do Estado de Bem-Estar firmaram-se vigorosas forças sindicais, instituíram-se, expandiram-se e multiplicaram-se direitos de cidadania e fortaleceram-se instituições democráticas.

Como se pode observar, o Estado de Bem-Estar tem como núcleo central a seguridade social. Por essa razão, foi somente a partir deste modelo que a saúde do indivíduo entrou na agenda pública. Antes disso, no Estado Liberal, o poder público agia tão somente no âmbito da 
saúde coletiva, a fim de oferecer saneamento e evitar epidemia, tendo em vista que o acesso aos serviços médicos era condicionado à possibilidade de quem poderia pagar por eles (AÑón, 2009). Como grande parte da população não dispunha dos recursos necessários para custear as prestações sanitárias, poucos eram os que tinham acesso aos cuidados médicos, os quais, como referido acima, eram quase que restritos aos trabalhadores e suas famílias.

Com o Plano Beveridge, instituiu-se um modelo de Sistema Nacional de Saúde não contributivo, universal e financiado pelos impostos. O direito à saúde passou, então, a ser titularizado por todos os indivíduos, que podiam se valer do Sistema Nacional sem qualquer contraprestação pecuniária e independente da comprovação da necessidade social. As bases da seguridade social foram modificadas.

Añón (2009, p. 24) afirma que uma característica das políticas do Estado de Bem-Estar Social “foi a participação do Estado na promoção e proteção da saúde da população, mediante a ampliação de sistemas públicos de saúde e pelo progressivo reconhecimento e positivação do direito à saúde" 82 . E é em razão do movimento estatal de maior proteção à saúde, que segundo Dallari (1995, p. 25):

No início do século XX se encontra instaurada a proteção sanitária como política de
governo. E são hierarquizadas três formas, hoje clássicas de prevenção: a primária,
que se preocupa com a eliminação das causas de condições de aparecimento das
doenças, agindo sobre o ambiente (segurança nas estradas, saneamento básico, por
exemplo) ou sobre o comportamento individual (exercício e dieta, por exemplo); a
secundária ou prevenção específica, que busca impedir o aparecimento de doença
determinada, por meio da vacinação, dos controles de saúde, da despistagem; e a
terciária, que visa limitar a prevalência de incapacidades crônicas ou de recidivas
(LEAVELL; CLARK, 1976) ${ }^{83}$. O Estado do bem-estar social da segunda metade do
século XX reforça a lógica econômica, especialmente em decorrência da evidente
interdependência entre as condições de saúde e de trabalho, responsabilizando-se pela
implementação da prevenção sanitária.
Instituem-se, então, os sistemas de previdência social, que não se limitam a cuidar dos
doentes, mas organizam a prevenção sanitária. A princípio, pressupunham uma
diferenciação entre assistência social, destinada às classes mais desfavorecidas e
baseada no princípio de solidariedade e, portanto, financiada por fundos públicos
estatais, e previdência social, mecanismo assecuratório restrito aos trabalhadores.
Entretanto, exatamente porque a prevenção sanitária era um dos objetivos do
desenvolvimento do Estado, logo se esclarece o conceito de seguridade social, que
engloba os subsistemas de assistência, previdência e saúde públicas. Trata-se,
portanto, de identificar a responsabilidade a priori do estado. Assim, quanto aos
estilos de vida, verifica-se um grande investimento estatal. À saúde foi conferida importância não somente no âmbito dos Estados, mas também no

\footnotetext{
${ }^{82}$ Tradução livre do trecho: “[...] ha sido la participación del Estado en la promoción y protección de la salud de la población, mediante la extensión de sistemas públicos de salud y mediante el progressivo reconocimiento y positivación de um derecho a la salud".

${ }^{83}$ Citação do próprio texto de Dallari (1995, p. 25).
} 
contexto internacional. Em 1946, foi criado um organismo específico para a sua proteção e promoção, a Organização Mundial da Saúde (OMS), que tem como objetivo promover a aquisição, por todos os povos, do nível de saúde mais elevado possível.

A Declaração Universal dos Direitos Humanos de 1948 também consagrou a saúde como direito humano essencial, prevendo que todo indivíduo tem direito a um padrão de vida capaz de assegurar a si e a sua família saúde e bem-estar, alimentação, vestuário, habitação, cuidados médicos e os serviços sociais indispensáveis.

O Pacto Internacional de Direitos Econômicos, Sociais e Culturais, por sua vez, realça que todos os Estados signatários reconhecem o direito de todos à fruição do mais alto nível de saúde física e mental. Eleva-se em nível internacional a questão acerca do significado da saúde, tema que, ao longo dos anos, tem suscitado inúmeras controvérsias e discussões.

O presente trabalho filia-se à conceituação adotada pela OMS, que no preâmbulo de sua Constituição define a saúde como o "estado completo de bem-estar físico, mental e social e não meramente a ausência de doença ou enfermidade" (ORGANIZAÇÃO MUNDIAL DA SAÚDE, 1946, p. 22).

Essa conceituação realça o caráter complexo e multifacetado da saúde, que não pode ser compreendida apenas como ausência de doenças, apesar de esta ser um elemento central, já que "afirma a existência de um núcleo preciso, orientando a compreensão do que, de forma clara e inquestionável, é direito subjetivo do indivíduo, ou seja, o da assistência integral, quer para tratar, quer para ainda readequar o indivíduo socialmente" (DALLARI; NUNES JÚNIOR, 2010, p. 10).

No entanto, a saúde é mais que isso, indo além da assistência médica e das ações para a promoção e manutenção de um estado saudável. Ela está relacionada com as próprias condições de vida das pessoas: meio ambiente, saneamento básico, moradia, alimentação, educação, trabalho, dentre outros.

Assim, o direito à saúde "parece não ser suscetível de uma consideração simplista, apresentando-se mais como um direito complexo, isso porque agrupa uma série de direitos diversos, ou porque se desdobra em uma série de elementos de diferente alcance" 84 (AÑóN, 2009, p. 41).

Nesse desiderato, o direito à saúde não pode ser compreendido na dimensão puramente

\footnotetext{
84 Tradução livre do trecho: "parece no ser suscetible de una consideración simplista y más bien se aparece como um derecho complejo, bien porque agrupa una serie de derechos diversos, o bien porque se despliegue en una serie de elementos de alcance diferente"
} 
individual, no sentido de que ser saudável depende tão somente do indivíduo. Ao contrário, envolve uma série de fatores individuais e coletivos, sendo a um só tempo direito individual e social. É individual porque envolve o direito de não sofrer violações por parte de terceiros e do Estado e social por exigir do governo a prestação de serviços públicos para a prevenção de doenças e para a promoção, proteção e recuperação da saúde.

O direito à saúde é também um bem coletivo, exigindo a participação da sociedade e do Estado na sua promoção, conforme bem realçado na Constituição da Organização Mundial da Saúde (1946, p. 2):

\footnotetext{
A saúde de todos os povos é fundamental para se alcançar a paz e a segurança e depende da mais ampla cooperação de indivíduos e Estados.

Os resultados alcançados por qualquer Estado na promoção e proteção da saúde são valiosos para todos.

A desigualdade dos diferentes países na promoção da saúde e no controle das doenças, especialmente as transmissíveis, constitui um perigo comum.

[...]

Os governos têm responsabilidade na saúde de seus povos, a qual só pode ser integralmente cumprida mediante a adoção de medidas sanitárias e sociais adequadas.
}

Destarte, no texto normativo da OMS, ao Estado e à sociedade é conferido o dever de criar condições econômicas, políticas e sociais para a promoção e proteção da saúde dos indivíduos. Esse aspecto é importante, na medida em que a saúde depende não apenas de aspectos pessoais (predisposição genética, características físicas, hábitos etc.), mas também das condições de vida que a sociedade e, em especial, o poder público proporcionam ao indivíduo.

A Constituição da OMS ressalta, também, a necessidade da comunhão de esforços dos Estados para efetivação do direito à saúde. Isso se deve ao fato de que, no mundo globalizado, o intenso fluxo de pessoas e mercadorias também favorece a difusão e propagação de doenças, de forma que o combate só será eficaz se todos empreenderem esforços para o alcance de um nível de desenvolvimento semelhante na proteção da saúde e no combate às doenças, sendo que “a extensão a todos os povos dos benefícios dos conhecimentos médicos, psicológicos e afins é essencial para a mais ampla realização da saúde" (ORGANIZAÇÃO MUNDIAL DA SAÚDE, 1946).

Como se vê, a Constituição da OMS, além de conceituar a saúde, apresenta muitos aspectos a ela relacionados, sendo um marco normativo muito importante para o estudo do tema, apesar das críticas que são feitas em virtude da suposta amplitude do texto. Añón (2009, p. 49-50) observa que:

Apesar de todos os inconvenientes, o conceito de saúde da OMS tem, frente às concepções anteriores de saúde, a vantagem de enfatizar determinados aspectos que 
não devem ser esquecidos, apresentando a novidade do abandono da visão puramente medicamentalizada: a proteção e promoção da saúde não é unicamente uma questão médica e tampouco limitada à assistência sanitária, uma vez que há outros esforços e políticas públicas que podem contribuir em grande medida com este objetivo. Assim, essa concepção integra a proteção da saúde em um marco geral, reconhecendo o seu duplo caráter individual e social (isto é, ainda que em última instância a saúde se refira à saúde dos indivíduos, existem fatores que são sociais - e o que talvez seja o mais importante, modificáveis - que incidem na mesma). Com isso, entende-se que a saúde implica também a existência de condições para o desenvolvimento das pessoas, sendo inseparável da paz, da eliminação da pobreza, da redução do desemprego, da preservação do meio ambiente, etc. Significa a existência de uma correlação entre saúde das pessoas e o desenvolvimento socioeconômico. Esta concepção se opõe a que se baseia na oposição saúde/enfermidade. E, além disso, neste sentido, parece frisar a possibilidade de ser guiada por estratégias não meramente curativas, mas também por estratégias amplas de promoção da saúde ${ }^{85}$.

O texto normativo da OMS é, portanto, referência obrigatória para a compreensão dos principais aspectos relacionados à saúde: conceito e complexidade; indissociabilidade das condições de vida das pessoas; caráter individual, social e coletivo; e a necessidade da participação da sociedade e do Estado na sua garantia.

\section{O DIREITO À SAÚDE NO BRASIL}

A Constituição Federal de 1988 foi o primeiro texto constitucional brasileiro a tratar a saúde como direito, inserindo-a no sistema da seguridade social, que, por sua vez, "compreende um conjunto integrado de ações de iniciativa dos Poderes Públicos e da sociedade, destinadas a assegurar os direitos relativos à saúde, à previdência e à assistência social” (art. 194) (BRASIL, 1988).

Ao contrário da previdência (de caráter contributivo) e da assistência social (prestada a quem está em situação de necessidade), a saúde se pauta pelo acesso universal, estando prevista

\footnotetext{
${ }^{85}$ Tradução livre do trecho: "A pesar de todos los inconvenientes, el concepto de salud de la OMS tiene unas ventajas y enfatiza determinados aspectos que non deben ser olvidados, frente a anteriores concepciones de la salude, presenta la novedad de abandonar la visión puramente medicalizada: proteger y promover la salud no es únicamente una cuestión médica ni limitada a la assistência sanitária, sino que hay otros esfuerzos y políticas públicas que pueden contribuir en gran medida a este objetivo. Así, esta concepción integra la proteción de la salud en un marco general, recogiendo su doble cara individual y social (es decir, aunque en última instancia la salud se refiere a la salud de os indivíduos, existen factores que son sociales - y lo que quizá sea má importante, modificables - que inciden en la misma). Con ello, se entiende que la salud implica también la existência de uns condiciones para el desarrollo de las personas y que resulta inseparable de la paz, la eliminación de la pobreza, la reducción del desempleo, la conservación del medio ambiente, etc. Significa atender a la existência de una correlación entre la salud de las personas e el desarrollo socioeconómico. Esta concepción se opone a la que se basa en la oposición salud/enfermedad, y que entiende simplesmente la salud como ausência de enfermedad. Y además, en este sentido, parece poner la vista en la posibilidad de guiarse por estrategias no meramente curaticvas, sino también amplias como la promoción de la salude".
} 
como "direito de todos e dever do Estado, garantido mediante políticas sociais e econômicas que visem à redução do risco de doença e de outros agravos e ao acesso universal e igualitário às ações e serviços para sua promoção, proteção e recuperação" (CF, art. 196). Souza (2013, p. 206-207) realça que:

[...] O mencionado dispositivo é o cerne do maior número de questões enfrentadas pelo operador jurídico que se depara com lides envolvendo a temática, gerando constantes tensões institucionais diante da pródiga interpretação que geralmente a ele é atribuída pelo Judiciário e da postura mais restritiva da Administração e dos gestores da saúde, premidos pelas limitações orçamentárias.

Tais tensões serão trabalhadas no capítulo seguinte do trabalho, valendo realçar desde logo que a saúde está prevista, ainda, no art. $6^{\circ}$ do texto constitucional, isto é, no rol dos direitos fundamentais sociais. No entanto, apesar de ser um direito social, o direito à saúde possui também uma dimensão subjetiva individual, sendo a um só tempo, portanto, um direito de viés programático e um direito oponível ao Estado judicialmente.

Na primeira parte do art. 196, pode-se perceber a institucionalização de um conceito amplo de saúde, incorporando-se ao contexto brasileiro a compreensão de saúde defendida desde 1948 pela Organização Mundial da Saúde, que, como visto, conceitua a saúde não apenas como a ausência de doença ou enfermidade, mas enquanto um estado de completo bem-estar físico e social.

Dessa forma, a Constituição, ao preceituar que a saúde deve ser garantida mediante políticas sociais e econômicas que visem à redução do risco de doença e de outros agravos, abandonou o entendimento puramente biológico da saúde que dominava as ações estatais na área, mais voltadas, até então, para a prevenção e o tratamento das doenças contagiosas. Segundo Santos (2010, p. 150):

O primeiro enunciado do artigo - execução de políticas sociais e econômicas
protetoras da saúde - vincula-se a planos e programas do Estado nacional, que devem
assegurar ao indivíduo e à coletividade tudo aquilo que possa ser considerado
essencial para a satisfação da saúde física, mental, psicológica, moral e social: morar
bem, ter salário digno, ter mais lazer, boa educação, alimentação suficiente,
segurança, previdência etc.

A saúde passou, assim, a não ser mais considerada de forma isolada, vale dizer, enquanto fenômeno relacionado somente ao homem, ao seu corpo e suas determinações genéticas. Albergou-se, também no conceito de saúde a relação do indivíduo com o ambiente social que o rodeia.

Nessa nova concepção, a saúde está interligada com o próprio modo de vida das pessoas, 
exigindo-se para a sua efetivação a garantia de: trabalho em condições dignas; alimentação para todos; moradia higiênica e digna; educação e informação plena; qualidade do meio ambiente; transporte seguro e acessível; repouso, lazer e segurança; direito à liberdade, à livre organização e expressão; e acesso universal e igualitário aos serviços setoriais em todos os níveis.

Em razão da correlação da saúde com fatores sociais, ambientais, econômicos e educacionais, a elaboração e execução das políticas sociais e econômicas protetoras da saúde não ficam restritas apenas ao sistema de saúde criado pela Constituição de 1988, envolvendo também outras pastas de governo, que devem trabalhar para "garantir às pessoas e à coletividade condições de bem-estar físico, mental e social”, através da promoção do acesso à alimentação, moradia, saneamento básico, meio ambiente, trabalho, renda, educação, atividade física, transporte, lazer e outros bens e serviços essenciais (Lei 8.080/90, art. $3^{\circ}$ ).

É o prescrito na segunda parte do art. 196 - a promoção do acesso universal e igualitário às ações e serviços para a promoção, proteção e recuperação da saúde - que se dirige mais especificamente ao sistema de saúde inaugurado pela ordem constitucional atual, qual seja: o Sistema Único de Saúde (SUS).

A Constituição de 1988 conceitua o SUS como uma rede regionalizada e hierarquizada de ações e serviços públicos de saúde (art. 198), traça algumas de suas diretrizes (art. 198 I a III) e atribuições (art. 200), fixa parâmetros de financiamento do sistema (art. $198 \S \S 1^{\circ}$ a $3^{\circ}$ ) e permite a atuação da iniciativa privada de forma complementar (art. 199).

Antes da criação do SUS, as ações e serviços de saúde eram divididos entre o Ministério da Saúde e o Ministério da Previdência e Assistência Social. O primeiro responsabilizava-se pelas ações preventivas e de caráter coletivo, enquanto o segundo cuidava da assistência médica, de caráter curativo, que era assegurada somente aos trabalhadores contribuintes da previdência.

A partir da Constituição de 1988 decidiu-se pela expansão e fortalecimento do setor público, bem como pela separação da saúde da previdência social. Com o SUS, os serviços e ações de saúde passaram a ser organizados em uma rede única, de acesso universal, isto é, a fruição dos serviços da rede independe de contribuição para o sistema. Souza (2013, p. 207, grifo nosso) aponta que:

O art. 198 é a matriz constitucional do sistema único de saúde, o SUS, rede regionalizada e hierarquizada de ações e serviços públicos de saúde que constituem um sistema único, organizado de acordo com as diretrizes da descentralização, com direção única em cada esfera de governo; do atendimento integral, com prioridade para as atividades preventivas, sem prejuízo dos serviços assistenciais e da participação da comunidade, sistema este responsável pelo oferecimento de mais de 
$75 \%$ da assistência à saúde da população brasileira.

Em 1990 foi promulgada a Lei 8.080, conhecida como a Lei Orgânica de Saúde, para o fim de regulamentar os dispositivos constitucionais explicitados, de modo a criar condições para a promoção, proteção e recuperação da saúde, a organização e o funcionamento dos serviços correspondentes.

O Sistema Único de Saúde é constituído, nos termos da Lei 8.080/90, pelo “conjunto de ações e serviços de saúde, prestados por órgãos e instituições públicas federais, estaduais e municipais, da Administração direta e indireta e das fundações mantidas pelo Poder Público". A iniciativa privada (preferencialmente as entidades filantrópicas e sem fins lucrativos) também poderá integrar o SUS em caráter complementar, quando a disponibilidade dos serviços públicos for insuficiente para garantir o acesso e a integralidade da assistência aos cidadãos, desde que sejam mantidos os princípios do sistema e mediante contrato de direito público ou convênio (AGUIAR, 2011).

No art. $7^{\circ}$ da Lei 8.080/90 estão previstos os seguintes princípios norteadores dos serviços e ações de promoção, proteção e recuperação da saúde: universalidade de acesso aos serviços de saúde; integralidade de assistência; preservação da autonomia das pessoas na defesa de sua integridade física e moral; igualdade da assistência à saúde, sem preconceitos ou privilégios de qualquer espécie; direito à informação; utilização da epidemiologia para o estabelecimento de prioridades, a alocação de recursos e a orientação programática; participação social; descentralização político-administrativa, com direção única em cada esfera de governo; integração em nível executivo das ações de saúde, meio ambiente e saneamento básico; conjugação dos recursos financeiros, tecnológicos, materiais e humanos dos entes federados; capacidade de resolução dos serviços em todos os níveis de assistência; e organização dos serviços públicos de modo a evitar duplicidade de meios para fins idênticos.

Sobre as diretrizes do SUS, é importante tecer maiores considerações sobre: a universalidade, igualdade, integralidade, unidade, descentralização e hierarquização.

O princípio constitucional da universalidade decorre do próprio caráter de direito fundamental que foi atribuído à saúde a partir do ordenamento de 1988. O direito à saúde aparece, portanto, como "um elemento intrínseco à dignidade do ser humano" (DALLARI; NUNES JÚNIOR, 2010, p. 72) e, por isso, pode ser exigido por todo o cidadão.

Desse modo, a assistência médica era de responsabilidade do Ministério de Previdência e Assistência Social, sendo prestada por meio do Instituto Nacional de Assistência Médica da Previdência Social (INAMPS) aos trabalhadores ou aos contribuintes autônomos do Instituto. 
As pessoas que estavam excluídas do mercado de trabalho ou que não podiam pagar as contribuições ao INAMPS estavam excluídas das prestações estatais de saúde. Em caso de doença, pagavam pelos serviços privados ou recorriam às instituições filantrópicas.

A Constituição de 1988 inseriu a saúde no capítulo da seguridade social, juntamente com a previdência e a assistência social. No entanto, a saúde pauta-se em princípios e diretrizes totalmente diferentes das observadas nas demais esferas. Enquanto a previdência tem caráter contributivo e a assistência social somente é prestada aos necessitados, a saúde tem acesso universal, devendo os serviços de prevenção e de assistência ser assegurados pelo Estado a toda a população. Dessa forma, conforme Weichert (2004, p. 158)

[...] O Sistema Único de Saúde não foi formulado apenas para a população carente (como uma política de assistência social) ou para os que contribuem à seguridade social (como uma prestação previdenciária), mas sim para a garantia de saúde a todos que necessitarem e desejarem a ele (o sistema público) recorrer [...].

Além do acesso universal, a Carta Magna previu o acesso igualitário aos serviços de saúde, o que significa que o acesso será assegurado a todos, sem distinções e privilégios. A adoção do princípio da igualdade nos serviços e ações de saúde nada mais é do que a concretização, que deve ocorrer na prestação de qualquer serviço público, da noção de igualdade refletida no caput do art. $5^{\circ}$ da CF e do princípio republicano insculpido no art. 19 III do texto constitucional, que veda a criação de distinções ou preferências entre brasileiros. Tal princípio pode ser sintetizado através da máxima segundo a qual a mesma situação clínica deve merecer a mesma atenção em saúde.

Serrano (2009, p. 76) adverte que "a conjugação dos princípios da universalidade e da igualdade acaba dando lugar à equidade”, que significa que devem ser reconhecidas as desigualdades na mortalidade e incidência de doenças entre os diferentes grupos sociais, de modo que as ações de saúde possam focar nos indivíduos mais vulneráveis (crianças, idosos, mulheres etc.), sem que isso represente afronta à igualdade preconizada no art. $5^{\circ}$ da $\mathrm{CF}$.

Outro princípio elencado no art. $7^{\circ}$ da Constituição Federal é o da integralidade, que, para Carvalho (2006), possui duas dimensões: horizontal e vertical. A primeira exige que haja a interligação de serviços de prevenção e tratamento, em âmbito individual e coletivo, devendo ser prestados em todos os níveis de complexidade. Já a dimensão vertical está relacionada ao conceito amplo de saúde, pressupondo "um olhar para as questões que envolvem o afetivo, o biológico, o espiritual, o sociocultural, entre outras" (CARVALHO, 2006, p. 16).

O princípio da unidade, por sua vez, traduz o objetivo do Sistema Único de Saúde de 
“articular todos os serviços existentes no país para que, atuando de forma ordenada, possa haver a otimização dos escassos recursos sociais em todos os níveis da federação, propiciando ganho de escala e evitando a sobreposição de estruturas" (SOUZA, 2013, p. 209).

É o princípio da unidade que permite ao cidadão recorrer, na falta dos serviços em sua localidade, aos serviços de saúde da municipalidade ou Estado vizinhos, bem como impede a “instrumentalização do sistema único pelo privado, proibindo que o paciente recorra ao sistema público exclusivamente para obter medicamentos, exames clínicos e tratamentos cirúrgicos prescritos por médico particular" (SOUZA, 2013, p. 210).

A descentralização, também, é um princípio organizativo do SUS, entendido como uma redistribuição de responsabilidades e recursos entre as três esferas de governo, com ênfase na municipalização, isto é, o Município é o principal responsável na garantia da saúde da população, somente podendo ser atribuídos aos Estados e à União os serviços que os Municípios não possam prestar, ou que tenham uma dimensão regional e nacional. Conforme Souza (2013, p. 213):

[...] Aqui se insere a acirrada discussão sobre a modalidade de responsabilidade dos entes federados, não nos parecendo ser o melhor entendimento aquele que prega a responsabilidade solidária indiscriminadamente entre a União, os Estados e os Municípios. Isso porque, a uma, a desconsideração das divisões de competências e responsabilidades estabelecidas nos atos normativos secundários e nas leis reguladores da matéria funcionam contra a diretriz da descentralização (objetivo historicamente perseguido pelo Movimento de Reforma Sanitária e pelo constituinte como melhor caminho para a melhoria global do sistema de saúde); e, a dois, porque a condenação incidente sobre diversos entes da federação gera desperdício de recursos em um ambiente já suficientemente marcado pela escassez.

A regionalização refere-se à forma de organização do sistema de saúde por circunscrições territoriais (de modo a levar-se em consideração o dinamismo e a complexidade dos perfis epidemiológicos locais), enquanto o princípio da hierarquização indica a necessidade de organizar o sistema por níveis de complexidade crescentes: primário (pequena complexidade - ex: consultas e curativos), secundário (média complexidade - ex: pequenas cirurgias) e terciário (alta complexidade - ex: cirurgias mais complexas).

As diretrizes da regionalização e da hierarquização possuem dois corolários: i) o estabelecimento de um sistema de atendimento afunilado, induzindo o usuário a ter o contato inicial com o nível primário de atendimento (a grande porta de entrada do sistema) para que a partir daí possa ser encaminhado aos níveis mais complexos (que possuem demanda decrescente e custo crescente em relação ao nível primário); e ii) o oferecimento seletivo de “[...] níveis de atendimento secundário e terciário em centros regionais capazes de atender à 
demanda de vários pequenos municípios, priorizando a alocação de recursos no nível primário de atendimento" (SOUZA, 2013, p. 211).

Todas essas diretrizes do SUS, estabelecidas na Constituição Federal e na Lei Orgânica da Saúde, são importantes marcos para a concretização do direito à saúde, vale dizer, para, diante da sua complexidade e multiplicidade de prestações, especificar o seu âmbito de abrangência, ou pelo menos, aquilo que o direito à saúde não comporta.

Dessa forma, faz-se necessário observar, por exemplo, que os ditames dos princípios da unidade, descentralização, hierarquia e regionalização do SUS são violados diante de determinadas decisões judiciais, como as que determinam o dispêndio de recursos públicos para o custeio de remédios, tratamentos e procedimentos prescritos exclusivamente por profissionais que não pertencia aos quadros do sistema público; as que são proferidas sem a análise minuciosa dos atos normativos de repartição de competência e responsabilidade; e as que condenam os municípios ao fornecimento de serviços de alta complexidade ou bens de alto custo. É importante realçar que a defesa da universalidade do direito à saúde não significa que toda e qualquer pretensão de bens ou serviços de saúde deva ser concedida pelo Poder Judiciário. É preciso haver uma racionalidade.

\section{CONSIDERAÇÕES FINAIS}

Destacou-se que o ápice do princípio da proteção social somente foi alcançado após a Segunda Guerra Mundial, quando o capitalismo, diante do quadro de instabilidade política, social e econômica mundial, precisou se reinventar, fundamentalmente pela necessidade de sua própria manutenção. Acabou por acolher demandas por maior igualdade, reconhecimento dos direitos sociais e segurança econômica, elementos decisivos no processo de constituição do Estado de Bem-Estar Social.

Constatou-se que no Estado de Bem-Estar Social cabe ao Poder Público, na concepção de Marshall (1967), a garantia de mínimos sociais e por conseguinte de direitos sociais que passam a estar inseridos no status da cidadania. Por sua vez, verificou-se que a seguridade social passou a ser o núcleo desse modelo de estado, por essa razão, foi somente a partir desse arquétipo organizacional que a saúde do indivíduo entrou na agenda pública como direito fundamental social.

Destacou-se que, no final da primeira metade do século $\mathrm{XX}$, à saúde foi conferida 
importância não somente no âmbito dos Estados, mas também no contexto internacional, essa ideia pode ser constatada com a criação de um organismo específico para a sua proteção e promoção a Organização Mundial da Saúde - OMS (1946), organismo que se estabeleceu com objetivo de promover a aquisição, por todos os povos, do nível de saúde mais elevado possível.

Evidenciou-se que no Brasil, a Constituição Federal de 1988 foi um marco decisivo na afirmação do direito à saúde, inserto em capítulo dirigido à seguridade social. Demonstrou-se que o direito à saúde está em condição diversa da previdência e da assistência sociais, na medida que se fundada nos princípios da igualdade e universalidade. Destacou-se, por conseguinte, a criação do Sistema Único de Saúde - SUS, que representou uma etapa peremptória no processo de conquistas e efetivação do direito à saúde.

Por fim, ressaltou-se que o conteúdo do direito à saúde não se resume a uma perspectiva biológica, condensada meramente na ideia de ausência de doença, na verdade está vinculado aos aspectos próprios do modo de vida das pessoas, exigindo-se para a sua efetivação a garantia de outros direitos fundamentais, quais sejam: trabalho em condições dignas; alimentação para todos; moradia higiênica e digna; educação e informação plena; qualidade do meio ambiente; transporte seguro e acessível; repouso, lazer e segurança; direito à liberdade, à livre organização e expressão; e acesso universal e igualitário aos serviços setoriais em todos os níveis.

\section{REFERÊNCIAS}

AÑón, Carlos Lena. Salud, justicia, derechos: el derecho a la salude como derecho social. Madri: Dyknson, 2009.

BRASIL. Constituição da República Federativa do Brasil de 1988. Disponível em: <http://www.planalto.gov.br/ccivil_03/constituicao/constituicao.htm>. Acesso em 5 fev. 2015 .

BRASIL. Lei 8.080, de 19 de setembro de 1990. Disponível em:

<http://www.planalto.gov.br/ccivil_03/leis/18080.htm>. Acesso em 5 fev. 2015.

CARVALHO, Gilson. Os governos trincam e truncam o conceito da integralidade. Radis, Rio de Janeiro, n. 49, ago. 2006. Disponível em:<http://www6.ensp.fiocruz.br/radis/revistaradis/49/reportagens/“os-governos-trincam-e-truncam-o-conceito-da-integralidade >. Acesso em: 12 maio 2015. 
DALLARI, Sueli Gandolf. Os estados brasileiros e o direito à saúde. São Paulo: Hucitec, 1995.

DALLARI, Sueli Gandolf; NUNES JÚNIOR, Vidal Serrano. Direito sanitário. São Paulo: Verbatim, 2010.

GIOVANNI, Geraldo di. Sistema de proteção social: uma introdução conceitual. In:

OLIVEIRA, Marco Antônio. (Org.). Reforma do Estado e políticas de emprego no Brasil. Campinas, São Paulo: UNICAMP, IE, 1998.

MARSHALL, Thomas Humphrey. Cidadania, classe social e status. Rio de Janeiro: Zahar, 1967.

ORGANIZAÇÃO MUNDIAL DA SAÚDE. Constituição da Organização Mundial da Saúde. São Paulo: Unesp, 1946. Disponível em: < http://www.direitoshumanos.usp.br/index.php/OMS-Organização-Mundial-daSaúde/constituicao-da-organizacao-mundial-da-saude-omswho.html>. Acesso em: 31 jan. 2015.

PEREIRA, Potyara Amazoneida Pereira. Política social: temas \&questões. São Paulo: Cortez, 2008.

POLANYI, Karl. A grande transformação: as origens de nossa época. 3. ed. Rio de Janeiro: Campus, 1980.

SANTOS, Lenir. Direito à saúde e Sistema Único de Saúde: conceito e atribuições. O que são ações e serviços de saúde. In: SANTOS, L (Org.). Direito da Saúde no Brasil. Campinas: Saberes, 2010. p. 145-179.

SERRANO, Mônica de Almeida Magalhães. O Sistema Único de Saúde e suas diretrizes constitucionais. São Paulo: Verbatim, 2009.

SOUZA, Jorge Munhós de. Diálogo institucional e direito à saúde. Salvador: JusPODIVM, 2013.

WEICHERT, Marlon Alberto. Saúde e federação na Constituição brasileira. Rio de Janeiro: Lumen Juris, 2004. 


\title{
A BRIEF REFLECTION ON THE CONSTRUCTION OF THE IDEA OF SOCIAL PROTECTION AND THE RIGHT TO HEALTH IN THE 1988 FEDERAL CONSTITUTION
}

\begin{abstract}
This article aims to perform an initial analysis of the right idea of the formulation process to health as a social right, part of the list of fundamental rights sculptured in the Federal Constitution of 1988. For both held a brief historical foray into the design of the building process social protection in the world. The purpose is also to analyze the social protection as a general factor of citizenship, social security as the core of the state Welfare and discuss the context of inclusion of the right to health issue on the public agenda. This paper uses the analytical method, through the appropriation of social protection concepts and social rights seeks a reflection on the determinations of the contents in the design of the right to health.
\end{abstract}

Keywords: Social Protection. Right to Health. Federal Constitution. 